TECHNICAL NOTES are short manuscripts describing new developments or important results of a preliminary nature. These Notes cannot exceed 6 manuscript pages and 3 figures; a page of text may be substituted for a figure and vice versa. After informal review by the editors, they may be published within a few months of the date of receipt. Style requirements are the same as for regular contributions (see inside back cover).

\section{Thrust Enhancement in Hypervelocity Nozzles by Chemical Catalysis}

\author{
D. J. Singh* \\ Analytical Services and Materials, Inc., \\ Hampton, Virginia 23666 \\ and \\ Mark H. Carpenter† and J. P. Drummond $\ddagger$ \\ NASA Langley Research Center, \\ Hampton, Virginia 23681-0001
}

\section{Introduction}

$\mathbf{I}^{\mathrm{N}}$ $\mathrm{N}$ the hypersonic flight regime, the air-breathing supersonic combustion ramjet (scramjet) has been shown to be a viable propulsion system. The current designs of scramjet engines provide performance benefits only up to a Mach number of 14.' Performance losses increase rapidly as the Mach number increases. To extend the applicability of scramjets beyond Mach 14, research is being conducted in the area of inlet and wave drag reduction, skin-friction and heat-transfer reduction, nozzle loss minimization, low-loss mixing, and combustion enhancement

For high Mach number applications, hydrogen is the obvious fuel choice because of its high energy content per unit mass in comparison with conventional fuels. These flight conditions require engines to operate at supersonic internal velocities, high combustor temperatures, and low static pressures. The high static temperature condition enhances the production of radicals such as $\mathrm{H}$ and $\mathrm{OH}$, and the low-pressure condition slows the reaction rates, particularly the recombination reactions. High-temperature and low-pressure constraints, in combination with a small residence time, result in a radical-rich exhaust gas mixture exiting the combustor. At high Mach number conditions (due to low residence time), $\mathrm{H}$ and $\mathrm{OH}$ do not have enough time to recombine; thus, a significant amount of energy is lost as these high-energy free radicals are exhausted. Therefore, any enhancement of recombination reactions will aid in recovering a part of the energy that would otherwise be lost.

One approach to enhancing the efficiency of hypersonic airbreathing propulsion systems is the manipulation of the chemistry by using additives, sensitizers, or excited species in the combustor. Twarowski ${ }^{2}$ showed that the presence of small

Received Feb. 13, 1995: revision received Dec. 4, 1996; accepted for publication April 3, 1997. This paper is declared a work of the U.S. Government and is not subject to copyright protection in the United States.

*Senior Research Scientist. 107 Research Drive; currently at Sverdrup Technology, 620 Discovery Drive, Huntsville, AL 35806.

+Research Scientist. Hypersonic Airbreathing Propulsion Branch, M/S 156

$\ddagger$ Senior Research Scientist, Hypersonic Airbreathing Propulsion Branch, M/S 156. amounts of phosphine combustion products in a combustion mixture containing $\mathrm{H}$ and $\mathrm{OH}$ radicals increases the recombination rates significantly at $1970 \mathrm{~K}$. In that study, Twarowski ${ }^{2}$ also assembled a mechanism for the reactions of phosphorus oxide and acid molecules, and estimated their reaction rates. Twarowski, ${ }^{3}$ in his follow-up study, showed that for fuel-rich combustion, the addition of $2-3$ wt $\%$ of phosphorus produced a specific impulse gain of $3-10 \mathrm{~s}$ for respective initial reactant temperatures of $1500-1000 \mathrm{~K}$.

The objective of the present study is to conduct a flowfield analysis for a typical nozzle geometry for a NASP-type vehicle to assess the prospects for thrust enhancement in hypervelocity nozzles by substituting small amounts of phosphine for hydrogen. A reaction sensitivity study of Twarowski's ${ }^{2}$ recently defined phosphorus chemistry is also conducted to identify the critical rate-limiting reactions.

\section{Governing Equations and Flow Conditions}

A quasi-one-dimensional Euler code written specifically for reacting-flow problems is used to analyze the flowfield. The governing equations are solved numerically with a three-stage Runge - Kutta method and a third-order upwind-biased scheme based on Roe's flux-splitting algorithm. The finite rate chemical reaction of phosphine, hydrogen, and air is modeled by a 14-species 33-reaction model, which was obtained from Ref. 2 and given in Table 1. The following flow conditions, which correspond to Mach 18 flight conditions, were chosen as the baseline conditions for the flow exiting the combustor at the nozzle throat: velocity $=5364 \mathrm{~m} / \mathrm{s}$, temperature $=3072 \mathrm{~K}$, pressure $=101,325 \mathrm{~N} / \mathrm{m}^{2}$, and fuel/air ratio $(\phi)=1.85$.

The total mass flow rate of fuel is kept constant. When phosphine is added to the fuel. it is substituted for hydrogen by mass. The total volume of fuel decreases as the percentage of phosphine increases because of its high density. A rectangular nozzle, representative for a $60-\mathrm{m}$ single-stage-to-orbit vehicle, is considered in this study. The nozzle has an inflow area of $0.1524 \mathrm{~m}^{2}$ and expansion ratio of 40 . The area expands rapidly with an expansion angle of $24 \mathrm{deg}$ for first $20 \%$ of nozzle length, and the expansion angle then reduces to $8.77 \mathrm{deg}$.

\section{Characteristic Time}

All chemical reactions have an associated characteristic time for which many definitions exist. A common measure is the time required for a major species involved in the reaction to reach a percentage of its equilibrium concentration. This definition requires the integration of a detailed chemical system from initial conditions to equilibrium. Because the primary motivation of this work is to determine chemical additions that decrease the characteristic reaction time of the hydrogen and air system, a precise measure of the characteristic time is needed to quantify the reaction system.

The chemical Jacobian is defined by $\partial w_{i} / \partial f_{j}$, where $w_{i}$ is the species production rate, and $f_{i}$ is the mass fraction of species $i$. It correlates the effects of species concentrations and reaction rates, and includes the entire spectrum of rate information that ranges from the rate-limiting reactions to those that react at the fastest rate. Transformation of the chemical Jacobian into diagonal form with the appropriate similarity transform yields the eigenvalues of the chemical reaction. Each eigenvalue corresponds to the characteristic time exhibited by a particular 


\section{Thrust Enhancement in Hypervelocity Nozzles by Chemical Catalysis D. J. Singh, M. H. Carpenter, J. P. Drummond}

\section{Reprinted from}

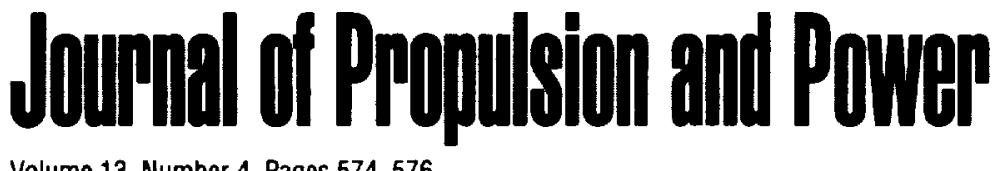

Volume 13 , Number 4, Pages 574-576

\section{OAIAA.}


Table 1 Reaction set and rate constants

\begin{tabular}{|c|c|c|c|c|c|}
\hline No. & Reaction" & $\log , A$ & $n$ & $E$ & $b$ \\
\hline 1 & $\mathrm{H}+\mathrm{H}+M \rightleftharpoons \mathrm{H}_{2}+M$ & 17.81 & -1.0 & 0 & - \\
\hline 2 & $\mathrm{O}+\mathrm{O}+M=\mathrm{O}_{2}+M$ & 17.00 & -1.0 & 0 & - \\
\hline 3 & $\mathrm{H}+\mathrm{O}+M=\mathrm{OH}+M$ & 16.42 & -0.6 & 0 & $\ldots$ \\
\hline 4 & $\mathrm{H}+\mathrm{OH}+M=\mathrm{H}_{2} \mathrm{O}+M$ & 21.92 & -2.0 & 0 & \\
\hline 5 & $\mathrm{H}+\mathrm{O}_{2}+M=\mathrm{HO}_{2}+M$ & 17.85 & -0.8 & 0 & \\
\hline 6 & $\mathrm{H}+\mathrm{O}_{2}=\mathrm{OH}+\mathrm{O}$ & 17.20 & -0.927 & 70.6 & \\
\hline 7 & $\mathrm{OH}+\mathrm{H}_{2}=\mathrm{H}_{2} \mathrm{O}+\mathrm{H}$ & 13.80 & 0 & 33.6 & \\
\hline 8 & $\mathrm{OH}+\mathrm{OH}=\mathrm{O}+\mathrm{H}_{2} \mathrm{O}$ & 8.320 & 1.4 & -1.7 & 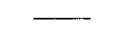 \\
\hline 9 & $\mathrm{O}+\mathrm{H}_{2}=\mathrm{OH}+\mathrm{H}$ & 14.27 & 0 & 57.0 & $-\cdots$ \\
\hline 10 & $\mathrm{HO}_{2}+\mathrm{H}=\mathrm{OH}+\mathrm{OH}$ & 14.34 & 0 & 5.9 & \\
\hline 11 & $\mathrm{HO}_{2}+\mathrm{H}=\mathrm{H}_{2}+\mathrm{O}_{2}$ & 13.4 & 0 & 2.9 & -- \\
\hline 12 & $\mathrm{HO}_{2}+\mathrm{O}=\mathrm{O}_{2}+\mathrm{OH}$ & 13.3 & 0 & 0 & \\
\hline 13 & $\mathrm{HO}_{2}+\mathrm{OH}=\mathrm{H}_{2} \mathrm{O}+\mathrm{O}_{2}$ & 13.3 & 0 & 0 & \\
\hline 14 & $\mathrm{O}_{2}+\mathrm{PO}+M=\mathrm{PO}_{4}+M$ & 13.5 & - & $\rightarrow$ & 0 \\
\hline 15 & $\mathrm{H}+\mathrm{PO}_{2}+M=\mathrm{HOPO}+M$ & 18.0 & - & & $8.860-04$ \\
\hline 16 & $\mathrm{H}+\mathrm{PO}+M=\mathrm{HPO}+M$ & 16.7 & $\ldots$ & - & $5.75 e-04$ \\
\hline 17 & $\mathrm{O}+\mathrm{PO}+M=\mathrm{PO}_{2}+M$ & 17.7 & $\longrightarrow$ & $\ldots$ & $7.15 \mathrm{e}-04$ \\
\hline 18 & $\mathrm{O}+\mathrm{PO}_{2}+M \rightleftharpoons \mathrm{PO}_{3}+M$ & 18.2 & 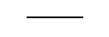 & $\longrightarrow$ & $9.23 \mathrm{e}-04$ \\
\hline 19 & $\mathrm{O}+\mathrm{HOPO}+M=\mathrm{HOPO}_{2}+M$ & 18.2 & - & $\cdots$ & $7.85 e-04$ \\
\hline 20 & $\mathrm{OH}+\mathrm{PO}+\mathrm{M}=\mathrm{HOPO}+M$ & 16.9 & - & $-\ldots$ & $4.80 \mathrm{c}-04$ \\
\hline 21 & $\mathrm{OH}+\mathrm{PO}_{2}+M=\mathrm{HOPO}_{2}+M$ & 20.5 & - & $\ldots$ & $1.19 \mathrm{e}-0.3$ \\
\hline 22 & $\mathrm{OH}+\mathrm{HPO} \rightleftharpoons \mathrm{H}_{2} \mathrm{O}+\mathrm{PO}$ & 11.5 & 0 & 7.5 & $\longrightarrow$ \\
\hline 23 & $\mathrm{O}+\mathrm{HOPO}=\mathrm{OH}+\mathrm{PO}_{2}$ & 13.5 & 0 & 8.3 & \\
\hline 24 & $\mathrm{H}+\mathrm{HOPO}=\mathrm{H}_{2} \mathrm{O}+\mathrm{PO}$ & 13.5 & 0 & 24.4 & $-\cdots$ \\
\hline 25 & $\mathrm{H}+\mathrm{HOPO}_{2}=\mathrm{H}_{2} \mathrm{O}+\mathrm{PO}_{2}$ & 13.5 & 0 & 0.2 & \\
\hline 26 & $\mathrm{H}_{2} \mathrm{O}+\mathrm{PO}_{3}=\mathrm{OH}+\mathrm{HOPO}_{2}$ & 11.5 & 0 & 0 & $\ldots$ \\
\hline 27 & $\mathrm{OH}+\mathrm{PO}=\mathrm{H}+\mathrm{PO}_{2}$ & 11.5 & 0 & 23.3 & \\
\hline 28 & $\mathrm{O}_{2}+\mathrm{PO}=\mathrm{O}+\mathrm{PO}_{2}$ & 11.5 & 0 & 22.2 & \\
\hline 29 & $\mathrm{O}+\mathrm{HOPO}_{2}=\mathrm{O}_{2}+\mathrm{HOPO}$ & 13.5 & 0 & 37.5 & - \\
\hline 30 & $\mathrm{H}+\mathrm{HOPO}=\mathrm{H}_{2}+\mathrm{PO}_{2}$ & 13.5 & 0 & 0.2 & $\cdots \cdots-$ \\
\hline 31 & $\mathrm{OH}+\mathrm{HOPO}=\mathrm{H}_{2} \mathrm{O}+\mathrm{PO}_{2}$ & 11.5 & 0 & 0 & $\longrightarrow$ \\
\hline 32 & $\mathrm{OH}+\mathrm{HOPO}=\mathrm{H}+\mathrm{HOPO}_{2}$ & 11.5 & 0 & 16.7 & $\cdots$ \\
\hline 33 & $\mathrm{PO}+\mathrm{HOPO}_{2}=\mathrm{PO}_{2}+\mathrm{HOPO}$ & 11.5 & 0 & 0 & \\
\hline
\end{tabular}

anits are kilojoules per mole, seconds, moles, cubic centimeters, and degrees Kelvin.

${ }^{b}$ Third-body efficiencies for all thermolecular reactions are 2.5 for $M=\mathrm{H}_{2}, 16.0$ for $\mathrm{H}_{2} \mathrm{O}$, and 1.0 for all other $M . K_{f}=A T^{\prime \prime} \exp (-E / R T)$ for reactions $1-13$ and $22-33$, and $A 10$ bT for reactions 14.21

reaction within the system. The largest and smallest eigenvalues correspond to the shortest and longest characteristic times. respectively. The overall reaction system is controlled by the rate-limiting reaction, which has the longest characteristic time.

Thus, to a first-order approximation, the smallest eigenvalue $\left(\lambda_{\min }\right)$ of the chemical Jacobian provides a measure of the overall limiting reaction rate of the chemical system, and the reciprocal of this eigenvalue determines the characteristic time $t_{c}$ of the system $\left(t_{c}=1 / \lambda_{\min }\right)$. In general, by perturbing any of the independent thermodynamic or species variables, and recalculating the smallest eigenvalue of the chemical Jacobian. we can establish the sensitivity of the characteristic time to the perturbation. The relative importance of the reactants and the products can thus be identified, as well as the necessary degree of precision for the reaction constants. Finally, the infiuence of chemical additives can be quantified by correlating the change of characteristic time with incremental changes of additive concentration.

\section{Results and Discussion}

A sensitivity study of the reaction mechanism used in the study is performed to identify the critical reactions and an assessment of their reaction rate uncertainty on the accuracy of the prediction is made. The results indicate the following:

Reaction 4:

$$
\mathrm{H}+\mathrm{OH}+M \rightleftharpoons \mathrm{H}_{2} \mathrm{O}+M
$$

is the most sensitive reaction. A $10 \%$ perturbation changes the limiting (longest) characteristic time by $3.8 \%$, which is the largest relative change among the 33 reactions. The second and third most sensitive reactions are, respectively, shown.
Reaction 30:

$$
\mathrm{H}+\mathrm{HOPO}=\mathrm{H}_{2}+\mathrm{PO}_{2}
$$

Reaction 15:

$$
\mathrm{H}+\mathrm{PO}_{2}+M=\mathrm{HOPO}+M
$$

For these reactions, the characteristic time is changed by 2.5 and $1.0 \%$, respectively. The rate constants for these reactions must be well established for accurate nozzle performance predictions.

Figures 1 and 2 show the ratio of limiting characteristic times as a function of temperature and percentage of phosphine in the fuel for $\phi=1.85$ (fuel rich) and $\phi=0.6$ (fuel lean) conditions. The ratio $t_{t} / t_{c}$ is the longest characteristic time without phosphine added to that with phosphine added. The efficiency of catalysis increases as the value of $t, d / t$, increases because of the decrease in $t$, for the rate limiting reaction. The ratio $t_{c 0} / t_{i}$ decreases as the temperature increases, and the ability of phosphine to enhance the recombination decreases as the temperature approaches about $3000 \mathrm{~K}$. This trend is in opposition to the desired result in the scramjet application. An optimum incremental amount of phosphine addition exists that gives the maximum decrease in $t_{i}$. Figure 1 shows that for the typical high Mach number fuel-rich $(\phi=1.85)$ combustor-exit conditions, such as those considered in the present study, the ratio $t_{t 0} / t_{c}$ is higher than fuel-lean conditions shown in Fig. 2. It shows that addition of phosphine will be more effective at fuel-rich conditions as opposed to fuel-lean conditions.

Flow computations were performed for several flow conditions. The baseline case was computed first, and then a parametric study was conducted by systematically varying the in 


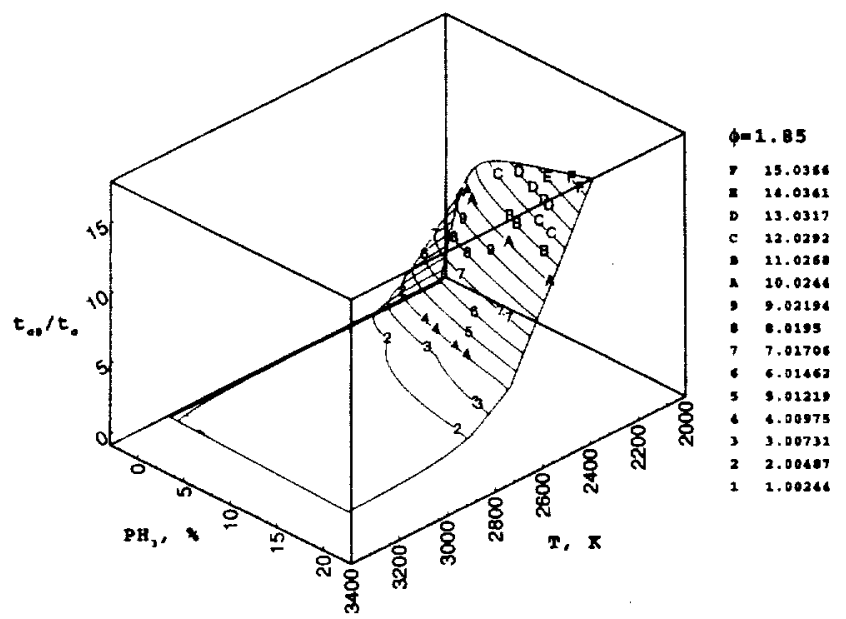

Fig. 1 Ratio of longest characteristic time with and without phosphine as function of temperature, and the percentage of phosphine in fuel reaction rates for $\phi=1.85$.

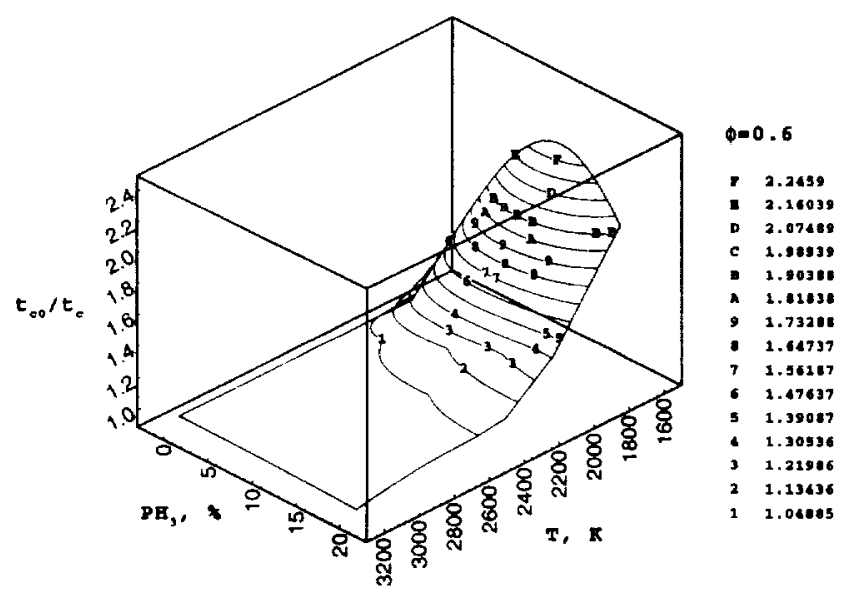

Fig. 2 Ratio of longest characteristic time with and without phosphine as function of temperature, and the percentage of phosphine in fuel reaction rates for $\phi=0.6$.

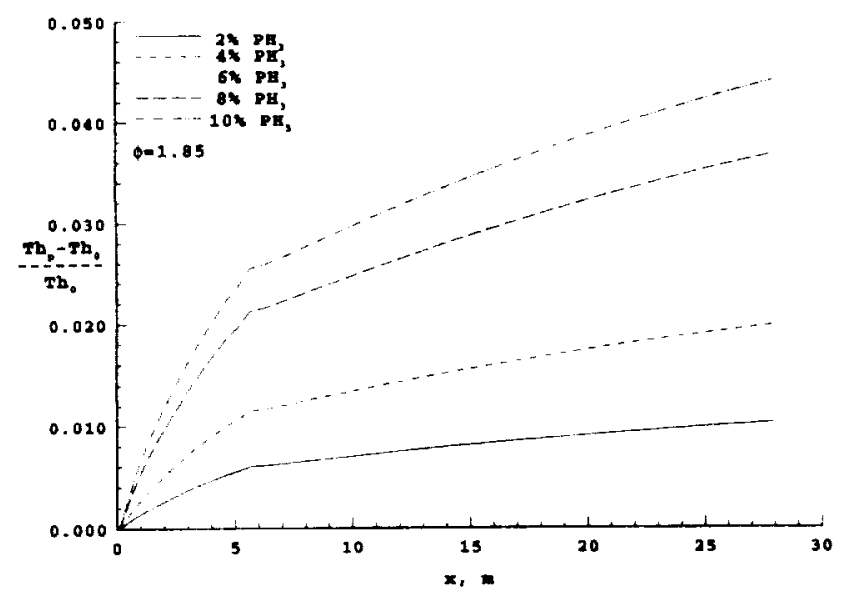

Fig. 3 Axial thrust with percentage of phosphine in fuel as parameter for $\phi=1.85$.

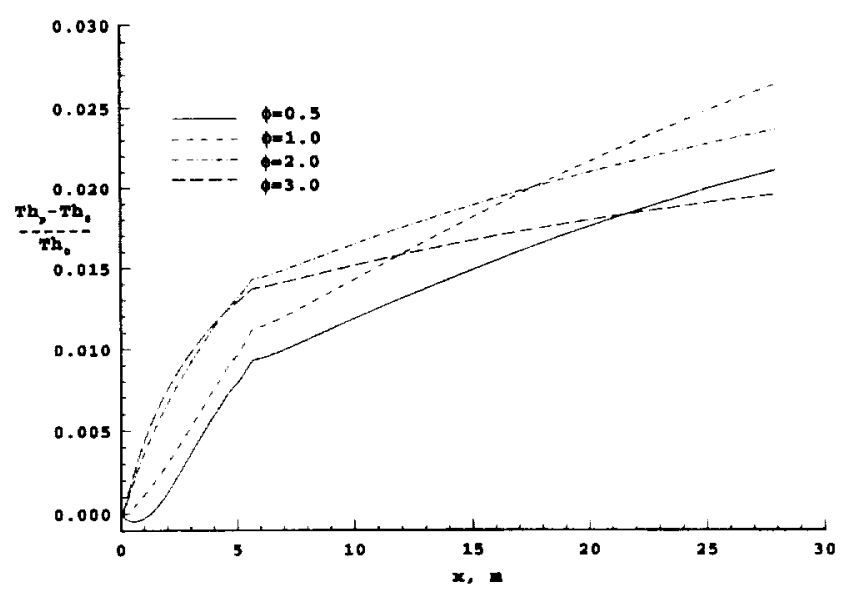

Fig. 4 Axial thrust with 5\% phosphine in fuel with $\phi$ as a parameter.

flow conditions. Axial distribution of normalized thrust because of the addition of phosphine at $\phi=1.85$ is shown in Fig. 3. The subscripts $p$ and 0 refer to the thrust $T h$ with and without phosphine addition, respectively. In the initial $20 \%$ of the nozzle section, the thrust increases very rapidly because of high flow expansion. As the amount of phosphine is increased, thrust production by the nozzle increases. It shows that $10 \%$ of phosphine addition enhances thrust by about $4.5 \%$. This is a significant enhancement, given the sensitivity of thrust, to vehicle performance.

Figure 4 shows the change in thrust caused by the $5 \%$ of phosphine addition, with $\phi$ ranging from 0.5 to 3.0 ; moreover, it shows that thrust enhancement is a strong function of $\phi$ and nozzle geometry. For a $10-\mathrm{m}$ nozzle maximum, thrust is produced for $\phi=2$, but on the other hand, if the nozzle is greater than $20 \mathrm{~m}, \phi=1$ produces maximum relative thrust.

\section{Conclusions}

A numerical study that used the quasi-one-dimensional Euler equations along with species conservation equations was conducted to study the possibility of thrust enhancement in hypersonic nozzles by substituting a small amount of phosphine for hydrogen to increase the recombination of $\mathrm{H}_{\lambda} \mathrm{O}$, radicals. The study showed that thrust production can be enhanced by phosphine addition. For nozzle inflow conditions corresponding to Mach 18 flight, the thrust can be enhanced by about $4.5 \%$.

\section{Acknowledgments}

The authors would like to thank G. L. Pellet, C. J. Jachimowski, and $G$. Anderson for their valuable suggestions.

\section{References}

'Menees, G. P., Adelman, H. G.. Cambier, J.-L.. and Bowles, J. V., "Wave Combustors for Trans-Atmospheric Vehicles," Journal of Propulsion and Power. Vol. 8, No. 3, 1992, pp. 709-71.3.

${ }^{2}$ Twarowski, A., "The Influence of Phosphorus Oxides and Acids on the Rate of $\mathrm{H}+\mathrm{OH}$ Recombination," Combustion and Flame. Vol. 94, Nos. 1/2, 1993, pp. $91-107$.

${ }^{3}$ Twarowski, A., "The Effect of Phosphorus Chemistry on Recombination Losses in a Supersonic Nozzle," Combustion and Flame, Vol. 102, Nos. 1/2, 1995, pp. 55-63. 